Pacific Journal of Mathematics

INVARIANT SUBSPACES OF POLYNOMIALLY COMPACT OPERATORS 


\title{
INVARIANT SUBSPACES OF POLYNOMIALLY COMPACT OPERATORS
}

\author{
P. R. Halmos
}

This paper is a comment on the solution of an invariant subspace problem by A. R. Bernstein and A. Robinson [2]. The theorem they prove can be stated as follows: if $A$ is an operator on a Hilbert space $H$ of dimension greater than 1, and if $p$ is a nonzero polynomial such that $p(A)$ is compact, then there exists a nontrivial subspace of $H$ invariant under $A$. ("Operator" means bounded linear transformation; "Hilbert space" means complete complex inner product space; "compact" means completely continuous; "subspace" means closed linear manifold; "nontrivial", for subspaces, means distinct from $\{0\}$ and from $H$.) The Bernstein-Robinson proof has two aspects: it is an ingenious adaptation of the proof by $N$. Aronszajn and $K$. T. Smith of the corresponding theorem for compact operators [1], and it makes strong use of metamathematical concepts such as nonstandard models of higher order predicate languages. The purpose of this paper is to show that by appropriate small modifications the Bernstein-Robinson proof can be converted (and shortened) into one that is expressible in the standard framework of classical analysis.

A quick glance at the problem is sufficient to show that there is no loss of generality in assuming the existence of a unit vector $e$ such that the vectors $e, A e, A^{2} e, \cdots$ are linearly independent and have $H$ for their (closed linear) span. (This comment appears in both [1] and [2].) The Gram-Schmidt orthogonalization process applied to the sequence $\left\{e, A e, A^{2} e, \cdots\right\}$ yields an orthonormal basis $\left\{e_{1}, e_{2}, e_{3}, \cdots\right\}$ with the property that the span of $\left\{e, \cdots, A^{n-1} e\right\}$ is the same as the span of $\left\{e_{1}, \cdots, e_{n}\right\}$ for each positive integer $n$. It follows that if $\mathrm{a}_{m n}=\left(A e_{n}, e_{m}\right)$, then $a_{m n}=0$ unless $m \leqq n+1$; in other words, in the matrix of $A$ all entries more than one step below the main diagonal must vanish. The matrix entries of the $k$ th power of $A$ are given by $a_{m n}^{(k)}=\left(A^{k} e_{n}, e_{m}\right)$. A straightforward induction argument, based on matrix multiplication, yields the result that $a_{m n}^{(k)}=0$ unless $m \leqq n+k$, and

$$
a_{n+k, n}^{(k)}=\Pi_{1 \leqq j \leqq k} a_{n+j, n+j-1} \text {. }
$$

(With the usual understanding about an empty product having the value 1 , the result is true for $k=0$ also.) This result for powers has an implication for polynomials. If the degree of $p$ (the only polynomial

Received October 10, 1964. Research supported in part by a grant from the National Science Foundation. 
needed) is $k(\geqq 1)$, and if the matrix entries of $p(A)$ are given by $a_{m n}^{(p)}=\left(p(A) e_{n}, e_{m}\right)$, then $a_{n+k, n}^{(p)}$ is a constant multiple (by the leading coefficient of $p$ ) of $a_{n+k, n}^{(k)}$. Since $\left\|p(A) e_{n}\right\| \rightarrow 0$ as $n \rightarrow \infty$ (because of the compactness of $p(A)$ ), there exists an increasing sequence $\{k(n)\}$ of positive integers (in fact a sequence with no gaps of length greater than the degree of $p$ ) such that the corresponding subdiagonal terms $a_{k(n)+1, k(n)}$ tend to 0 as $n$ tends to $c$. (This very useful conclusion is one of the analytic tools used in [2], where it is described in terms of "infinite positive integers".)

If $H_{n}$ is the span of $\left\{e_{1}, \cdots, e_{k(n)}\right\}$, then $\left\{H_{n}\right\}$ is an increasing sequence of finite-dimensional subspaces of $H$ whose span is $H$. If $P_{n}$ is the projection with range $H_{n}$, then $P_{n} \rightarrow 1$ (the identity operator) strongly. Since, for each $n$, the operator $P_{n} A P_{n}$ leaves $H_{n}$ invariant, it follows that, for each $n$, there exists a chain of subspaces invariant under $P_{n} A P_{n}$,

$$
\{0\}=H_{n}^{(0)} \subset H_{n}^{(1)} \subset \cdots \subset H_{n}^{(k(n))}=H_{n},
$$

with $\operatorname{dim} H_{n}^{(i)}=i, \quad i=0,1, \cdots, k(n)$. (The consideration of such chains is essential in both [1] and [2].)

If $\left\{f_{n}\right\}$ and $\left\{g_{n}\right\}$ are sequences of vectors in $H$, it is convenient to write $f_{n} \sim g_{n}$ to mean that $\left\|f_{n}-g_{n}\right\| \rightarrow 0$ as $n \rightarrow \infty$. Assertion: if $\left\{f_{n}\right\}$ is a bounded sequence of vectors in $H$, then

$$
A P_{n} f_{n} \sim P_{n} A P_{n} f_{n} .
$$

(Intuitively: $H_{n}$ is approximately invariant under $A$.) The proof is a straightforward computation, based on the fact that $P_{n} f=\sum_{j=1}^{k(n)}\left(f, e_{j}\right) e_{j}$ whenever $f \in H$. Since $A P_{n} f_{n}-P_{n} A P_{n} f_{n}=\sum_{j=1}^{k(n)}\left(f_{n}, e_{j}\right) \sum_{i=k(n)+1}^{\infty} a_{i j} e_{i}$, since the largest $j$ here is $k(n)$ and the smallest $i$ is $k(n)+1$, and since $a_{i j}=0$ unless $i \leqq j+1$, it follows that $\left\|A P_{n} f_{n}-P_{n} A P_{n} f_{n}\right\| \leqq$ $\left\|f_{n}\right\| \cdot\left|a_{k(n)+1, k(n)}\right| \cdot$

The conclusion (1) can be generalized to higher exponents:

$$
A^{k} P_{n} f_{n} \sim\left(P_{n} A P_{n}\right)^{k} f_{n}, \quad k=1,2,3, \cdots ;
$$

the proof is by induction on $k$ and is omitted. For $k=0$, (2) says that $\left\|P_{n} f_{n}-f_{n}\right\| \rightarrow 0$, which is a stringent condition on the bounded sequence $\left\{f_{n}\right\}$; if that condition is satisfied, then (2) implies that

$$
p(A) P_{n} f_{n} \sim p\left(P_{n} A P_{n}\right) f_{n} .
$$

Return now to the unit vector $e$. Since $P_{n} e=e$ for each $n$, it follows that $p\left(P_{n} A P_{n}\right) e \sim p(A) e$. Since $p(A) e \neq 0$ (because the vectors $e, A e, A^{2} e, \cdots$ are linearly independent), it follows that

$$
\varepsilon=\lim _{n}\left\|p\left(P_{n} A P_{n}\right) e\right\|=\|p(A) e\|>0 \text {. }
$$

Consider, for each $n$, the numbers 


$$
\begin{gathered}
\left\|p\left(P_{n} A P_{n}\right) e-p\left(P_{n} A P_{n}\right) P_{n}^{(0)} e\right\|, \\
\left\|p\left(P_{n} A P_{n}\right) e-p\left(P_{n} A P_{n}\right) P_{n}^{(1)} e\right\|, \\
\cdots \\
\left\|p\left(P_{n} A P_{n}\right) e-p\left(P_{n} A P_{n}\right) P_{n}^{(k(n))} e\right\|,
\end{gathered}
$$

where $P_{n}^{(i)}$ is the projection with range $H_{n}^{(i)}$. Since $P_{n}^{(0)}$ is the zero projection, the first of these numbers tends to $\varepsilon$. Since, on the other hand, $P_{n}^{(k(n))}=P_{n}$, the last of these numbers is always 0 . In view of these facts it is possible to choose for each $n$ (with possibly a finite number of exceptions) a positive integer $i(n), 1 \leqq i(n) \leqq k(n)$, such that

$$
\left|p\left(P_{n} A P_{n}\right) e-p\left(P_{n} A P_{n}\right) P_{n}^{(i(n)-1)} e\right| \geqq \frac{\hat{\varepsilon}}{2},
$$

and

$$
\left\|p\left(P_{n} A P_{n}\right) e-p\left(P_{n} A P_{n}\right) P_{n}^{(i(n))} e\right\|<\frac{\varepsilon}{2} ;
$$

the simplest way to do it is to let $i(n)$ be the smallest positive integer for which these inequalities are true. (The construction of this particular "infinite positive integer" $i$ is the second major analytic insight in [2].)

Since both $\left\{P_{n}^{(i(n)-1)}\right\}$ and $\left\{P_{n}^{(i(n))}\right\}$ are bounded sequences of operators, there exists an increasing sequence $\left\{n_{j}\right\}$ of positive integers such that both $\left\{P_{n_{j}}^{\left(i\left(n_{j}\right)-1\right)}\right\}$ and $\left\{P_{n_{j}}^{\left(i\left(n_{j}\right)\right)}\right\}$ are weakly convergent. Write, for typographical convenience, $Q_{j}^{-}=P_{n_{j}}^{\left(i\left(n_{j}\right)-1\right)}$ and $Q_{j}^{+}=P_{n_{j}}^{\left(i\left(n_{j}\right)\right)}$. Let $M^{-}$be the set of all those vectors $f$ in $H$ for which $Q_{j}^{-} f \rightarrow f$ (strongly), and, similarly, let $M^{+}$be the set of those vectors $f$ for which $Q_{j}^{+} f \rightarrow f$ (strongly). The purpose of what follows is to prove that both $M^{-}$ and $M^{+}$are subspaces of $H$, that both are invariant under $A$, and that at least one of them is nontrivial.

Since linear combinations are continuous, it follows that $M^{-}$is a linear manifold. To prove that $M^{-}$is closed, suppose that $g$ is in the closure of $M^{-}$; it is to be proved that $g \in M^{-}$, i.e., that $Q_{j}^{-} g \rightarrow g$. Given a positive number $\delta$, find $f$ in $M^{-}$so that $\|f-g\|<\delta / 3$, and then find $j_{0}$ so that $\left\|Q_{j} f-f\right\|<\delta / 3$ whenever $j \geqq j_{0}$. It follows that if $j \geqq j_{0}$, then $\left\|Q_{j}^{-} g-g\right\| \leqq\left\|Q_{j}^{-} g-Q_{j}^{-} f\right\|+\left\|Q_{j}^{-} f-f\right\|+\|f-g\|<\delta$. This proves that $M^{-}$is closed; the proof for $M^{+}$is the same.

To prove that $M^{-}$is invariant under $A$, suppose that $f \in M^{-}$, so that $Q_{j}^{-} f \rightarrow f$, and infer, first, that $A Q_{j}^{-} f \rightarrow A f$, just because $A$ is bounded, and, second, that $Q_{j}^{-} A Q_{j}^{-} f \sim Q_{j}^{-} A f$, because $Q_{j}^{-}$is uniformly bounded. Then reason as follows: $Q_{j}^{-} A f \sim Q_{j}^{-} A Q_{j}^{-} f=Q_{j}^{-} P_{n j} A P_{n j} Q_{j}^{-} f$ (because $Q_{j}^{-} \leqq P_{n j}$ ) $=P_{n j} A P_{n j} Q_{j}^{-} f$ (because the range of $Q_{j}^{-}$is invariant 
under $\left.P_{n j} A P_{n_{j}}\right) \sim A P_{n_{j}} Q_{j}^{-} f$ (by (1)) $=A Q_{j}^{-} f \rightarrow A f$. This proves that $M^{-}$is invariant; the proof for $M^{-}$is the same.

The next step is to prove that $M^{-} \neq H$; this is done by proving that $e$ does not belong to $M^{-}$. For this purpose observe first that the operators $p\left(P_{n} A P_{n}\right)$ are uniformly bounded. (Observe that

$$
\left\|\left(P_{n} A P_{n}\right)^{k}\right\| \leqq\left\|P_{n} A P_{n}\right\|^{k} \leqq\|A\|^{k}
$$

and use the polynomial whose coefficients are the absolute values of the coefficients of $p$.) Now use (4):

$$
\frac{\varepsilon}{2} \leqq\left\|p\left(P_{n_{j}} A P_{n_{j}}\right)\right\| \cdot\left\|e-Q_{j}^{-} e\right\| \cdot
$$

Since $\left\|p\left(P_{n_{j}} A P_{n_{j}}\right)\right\|$ is bounded from above, its reciprocal is bounded away from zero, and, consequently, $\left\|e-Q_{j}^{-} e\right\|$ is bounded away from zero, which makes the convergence $Q_{j}^{-} e \rightarrow e$ impossible.

The corresponding step for $M^{+}$says that $M^{+} \neq\{0\}$; the proof is quite different. The choice of the sequence $\left\{n_{j}\right\}$ implies that the sequence $\left\{Q_{j}^{+} e\right\}$ is weakly convergent; the compactness of $p(A)$ implies, therefore, that the sequence $\left\{p(A) Q_{j}^{+} e\right\}$ is strongly convergent to, say, $f$. The proof that follows consists of two parts: . (i) $f \neq 0$, (ii) $f \in M^{+}$. Part (i): $p(A) Q_{j}^{+} e \sim p\left(P_{n_{j}} A P_{n_{j}}\right) Q_{j}^{+} e$ (by (3)), which is within $\varepsilon / 2$ of $p\left(P_{n g} A P_{n_{j}}\right) e$ (by (5)), whose norm tends to $\varepsilon$; it follows that $\left\|p(A) Q_{j}^{+} e\right\|^{\prime}$ cannot tend to 0 , and hence that $f \neq 0$. Part (ii): $Q_{j}^{+} f \sim Q_{j}^{+} p(A) Q_{j}^{+} e$ (since $Q_{j}^{+}$is uniformly bounded) $\sim Q_{j}^{+} p\left(P_{n_{j}} A P_{n_{j}}\right) Q_{j} e^{-}$(by (3), and, again, uniform boundedness) $=p\left(P_{n_{j}} A P_{n_{j}}\right) Q_{j} e$ (because the range of $Q_{j}^{+}$is invariant under $\left.p\left(P_{n_{j}} A P_{n_{j}}\right)\right) \sim p(A) Q_{j}^{+} e$ (by (3)) $\rightarrow f$ (by definition).

If $M^{+} \neq H$, all is well; it remains to be proved that if $M^{+}=H$, then $M^{-} \neq\{0\}$. If $M^{+}=H$, then $Q_{j}^{+} f \rightarrow f$ for all $f$, and, a fortiori, $Q_{j}^{+} f \rightarrow f$ weakly. At the same time the sequence $\left\{Q_{j}^{-}\right\}$is known to be weakly convergent to, say, $Q^{-}$. The operators $Q_{j}^{-}$and $Q_{j}^{+}$are projections such that $Q_{j}^{-} \leqq Q_{j}^{-}$and such that $Q_{j}^{-}-Q_{j}^{-}$has rank 1 . It follows that, for each $j$, there exists a unit vector $f_{j}$ such that $\left(Q_{j}^{+}-Q_{j}^{-}\right) f=\left(f, f_{j}\right) f_{j}$ for all $f$. Observe now that $Q_{j}^{-} e$ cannot tend weakly to $e$, for, if it did, then it would tend strongly to $e$ (an elementary property of projections), and that was proved to be not so. This implies that $Q^{-} e \neq e$, or, equivalently, that $\left(1-Q^{-}\right) e \neq 0$. Can the numbers $\left|\left(e, f_{j}\right)\right|$ be arbitrarily small? Since $\left|\left(\left(Q_{j}^{-}-Q_{j}^{-}\right) e, g\right)\right| \leqq$ $\left|\left(e, f_{j}\right)\right| \cdot\|g\|$ for all $g$, an affirmative answer would imply that $\left(\left(1-Q^{-}\right) e, g\right)=0$ for all $g$, so that $\left(1-Q^{-}\right) e=0-$ a contradiction. The fact so obtained (that the numbers $\left|\left(e, f_{j}\right)\right|$ are bounded away from zero) makes it possible to prove that $M^{-} \neq\{0\}$; it turns out that if $g \perp\left(1-Q^{-}\right) e$, then $g \in M^{-}$. Indeed, since $\left(e, f_{j}\right)\left(f_{j}, g\right) \rightarrow\left(\left(1-Q^{-}\right) e, g\right)=$ 0 , it follows that $\left(f_{j}, g\right) \rightarrow 0$, and hence that $\left(f, f_{j}\right)\left(f_{j}, g\right) \rightarrow 0$ for all 
$f$. This implies that $\left(\left(1-Q^{-}\right) f, g\right)=0$ for all $f$, and hence that $\left(1-Q^{-}\right) g=0$. In other words, $Q_{j}^{-} g \rightarrow g$ weakly, and therefore strongly (the same property of projections that was alluded to above); from this it follows, finally, that $g \in M^{-}$.

I am grateful to Professor Robinson for a prepublication copy of [2] and for a kind letter helping me over some metamathematical difficulties.

\section{REFERENCES}

1. N. Aronszajn and K. T. Smith, Invariant subspaces of completely continuous operators, Ann. Math. 60 (1954), 345-350.

2. A. R. Bernstein and A. Robinson, Solution of an invariant subspace problem of K. T. Smith and P. R. Halmos.

UNIVERSITY OF MICHIGAN 



\section{PACIFIC JOURNAL OF MATHEMATICS}

\section{EDITORS}

\author{
H. SAMmLSON \\ Stanford University \\ Stanford, California \\ R. M. BLUMENTHAL \\ University of Washington \\ Seattle, Washington 98105
}

\author{
*J. DUGUNDJI \\ University of Southern California \\ Los Angeles, California 90007
}

RICHARD ARENS

University of California

Los Angeles, California 90024

\section{E. F. BECKENBACH \\ B. H. NEUMANN \\ ASSOCIATE EDITORS}

\section{SUPPORTING INSTITUTIONS}

\author{
UNIVERSITY OF BRITISH COLUMBIA \\ CALIFORNIA INSTITUTE OF TECHNOLOGY \\ UNIVERSITY OF CALIFORNIA \\ MONTANA STATE UNIVERSITY \\ UNIVERSITY OF NEVADA \\ NEW MEXICO STATE UNIVERSITY \\ OREGON STATE UNIVERSITY \\ UNIVERSITY OF OREGON \\ OSAKA UNIVERSITY \\ UNIVERSITY OF SOUTHERN CALIFORNIA
}

\author{
STANFORD UNIVERSITY \\ UNIVERSITY OF TOKYO \\ UNIVERSITY OF UTAH \\ WASHINGTON STATE UNIVERSITY \\ UNIVERSITY OF WASHINGTON \\ * * * \\ AMERICAN MATHEMATICAL SOCIETY \\ CHEVRON RESEARCH CORPORATION \\ TRW SYSTEMS \\ NAVAL ORDNANCE TEST STATION
}

\footnotetext{
Mathematical papers intended for publication in the Pacific Journal of Mathematics should be typewritten (double spaced). The first paragraph or two must be capable of being used separately as a synopsis of the entire paper. It should not contain references to the bibliography. Manu. scripts may be sent to any one of the four editors. All other communications to the editors should be addressed to the managing editor, Richard Arens at the University of California, Los Angeles, California 90024.

50 reprints per author of each article are furnished free of charge; additional copies may be obtained at cost in multiples of 50 .
}

The Pacific Journal of Mathematics is published monthly. Effective with Volume 16 the price per volume (3 numbers) is $\$ 8.00$; single issues, $\$ 3.00$. Special price for current issues to individual faculty members of supporting institutions and to individual members of the American Mathematical Society: $\$ 4.00$ per volume; single issues $\$ 1.50$. Back numbers are available.

Subscriptions, orders for back numbers, and changes of address should be sent to Pacific Journal of Mathematics, 103 Highland Boulevard, Berkeley 8, California.

Printed at Kokusai Bunken Insatsusha (International Academic Printing Co., Ltd.), No. 6, 2-chome, Fujimi-cho, Chiyoda-ku, Tokyo, Japan.

PUBLISHED BY PACIFIC JOURNAL OF MATHEMATICS, A NON-PROFIT CORPORATION

The Supporting Institutions listed above contribute to the cost of publication of this Journal, but they are not owners or publishers and have no responsibility for its content or policies.

* Paul A. White, Acting Editor until J. Dugundji returns. 


\section{Pacific Journal of Mathematics}

\section{Vol. 16, No. $3 \quad$ BadMonth, 1966}

Gert Einar Torsten Almkvist, Stability of linear differential equations with

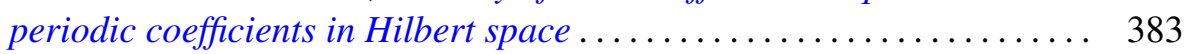

Richard Allen Askey and Stephen Wainger, A transplantation theorem for ultraspherical coefficients ................................ 393

Joseph Barback, Two notes on regressive isols .................. 407

Allen Richard Bernstein and Abraham Robinson, Solution of an invariant subspace problem of K. T. Smith and P. R. Halmos .............. 421

P. R. Halmos, Invariant subspaces of polynomially compact operators . . . . 433

Leon Bernstein, New infinite classes of periodic Jacobi-Perron algorithms.................................... 439

Richard Anthony Brualdi, Permanent of the direct product of matrices .... . 471

W. Wistar (William) Comfort and Kenneth Allen Ross, Pseudocompactness and uniform continuity in topological groups .................. 483

James Michael Gardner Fell, Algebras and fiber bundles . . . . . . . . . . . . 497

Alessandro Figà-Talamanca and Daniel Rider, A theorem of Littlewood and lacunary series for compact groups ..................... 505

David London, Two inequalities in nonnegative symmetric matrices...... 515

Norman Jay Pullman, Infinite products of substochastic matrices ........ 537

James McLean Sloss, Reflection and approximation by interpolation along

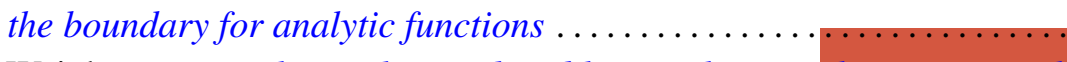

Carl Weinbaum, Visualizing the word problem, with an application to sixth groups................................... 